\title{
Immune deficiency due to adenosine deaminase and purine nucleoside phosphorylase deficiency: a simple diagnostic test
}

\author{
JL MADDOCKS, SA AL-SAFI, G WILSON \\ From the University Department of Therapeutics, Royal Hallamshire Hospital, Sheffield S10 2JF
}

SUMmARY A simple method is described for diagnosing adenosine deaminase and purine nucleoside phosphorylase deficiency using urine. Cellulose thin layer chromatography of $1 \mu l$ of urine from affected children was performed and deoxyadenosine and deoxyguanosine were easily detected by phosphorescence at the temperature of liquid nitrogen. This test is not expensive and can be done in any laboratory. It should be suitable for diagnostic screening in patients with immune deficiency.

Severe recurrent infections in childhood may occur as a result of defects in the immune system. A major advance by Giblett et al was the discovery that these may be due to a deficiency in enzymes involved in recycling purines: adenosine deaminase ${ }^{1}$ (EC $3 \cdot 5 \cdot 4 \cdot 4$ ) and purine nucleoside phosphorylase ${ }^{2}$ (EC $2 \cdot 4 \cdot 2 \cdot 1)$. Without treatment both these conditions are usually fatal.

Adenosine deaminase deficiency results in lack of both humoral and cellular immunity. It is associated with recurrent bacterial, viral, fungal and protozoan infections starting within weeks or months of birth. Patients pass urine containing abnormally high concentrations of deoxyadenosine. ${ }^{3-5}$ In purine nucleoside phosphorylase deficiency children have a selective defect in cellular immunity and suffer from repeated viral and fungal infections. Deoxyguanosine in high concentrations is found in their urine. ${ }^{67}$

Two methods of diagnostic screening are available for these conditions: enzyme analysis ${ }^{8-11}$ and detection and measurement of abnormal purines by isotachophoresis and high performance liquid chromatography. ${ }^{3}$ They require technical expertise and special equipment.

We report a simple and cheap method for diagnostic screening of urine for these disorders by thin layer chromatography. Adenosine phosphoresces strongly at the temperature of liquid nitrogen $\left(-196^{\circ} \mathrm{C}\right), 1^{12}$ and we have used this property for

Accepted for publication 24 July 1984 detecting deoxyadenosine and deoxyguanosine. It is an extremely sensitive detection method.

\section{Material and methods}

Urine samples from a child (SY) aged 2 months with adenosine deaminase deficiency and another (SB) aged 3 months with purine nucleoside phosphorylase deficiency were supplied by Dr Anne Simmonds, Guy's Hospital, London. Both were obtained before drug treatment. They were transported in solid carbon dioxide and stored at $-20^{\circ} \mathrm{C}$ until used, as deoxyadenosine and deoxyguanosine are unstable in acid urine at room temperature. ${ }^{13}$ Control urine samples (50) were obtained from children with various diseases treated at Sheffield Children's Hospital.

Deoxyadenosine, deoxyguanosine and other chemicals used were obtained from Sigma Chemical Company, Dorset. Stock solutions of $1 \mathrm{mmol} / \mathrm{l}$ were prepared in water and in urine and stored at $4^{\circ} \mathrm{C}$. They were replaced every two weeks. Cellulose thin layers (Art 5552) supplied by Merck, Darmstadt, were $0.1 \mathrm{~mm}$ thick. They were non-activated, without fluorescent indicator, and mounted on aluminium sheets. Those mounted on plastic were less satisfactory owing to high background phosphorescence.

One microlitre samples of urine and standard solutions of nucleosides were applied with a microlitre syringe over a $1 \mathrm{~cm}$ line, which was $2 \mathrm{~cm}$ from the edge of the sheet.

The most effective solvent system for separation of deoxyadenosine and deoxyguanosine from other 
urinary constituents was sodium acetate $(3 \%)$ containing lithium chloride $(3 \mathrm{~g} / 100 \mathrm{ml})$ : methanol (30:70 vol/vol). Development of the chromatogram to $12 \mathrm{~cm}$ took 100 minutes. Detection of phosphorescent compounds was carried out in a polystyrene box which had been painted with black. ${ }^{14} \mathrm{~A}$ central well had been cut out of the floor of the box to hold liquid nitrogen and this was covered by a black painted steel plate. The chromatogram was then placed on the steel plate in the box and liquid nitrogen was poured over it until it was just covered. The chromatogram was viewed in a dark room after exposing it to ultraviolet light $(254 \mathrm{~nm})$ for a few seconds. The colour of the phosphorescent bands was noted and the duration of light emission was measured by eye using a stop watch. As the phosphorescence of deoxyadenosine and deoxyguanosine is affected by $\mathrm{pH}$, the effect of spraying the chromatogram with $1 \mathrm{~N}$ hydrochloric acid was also noted.

A permanent record of the phosphorescence was obtained by laying a medical $x$ ray film (Singul-X $R P$, Ceaverken AB, Sweden) on to the chromatogram as soon as the ultraviolet light had been switched off and exposing the film for $20 \mathrm{~s}$.
Results

Deoxyadenosine was easily detected in the urine of the child (SY) with adenosine deaminase deficiency and deoxyguanosine in the urine of the child (SB) with purine nucleoside phosphorylase deficiency (Figure). These compounds were absent in 30 samples of normal urine and in the urine of 50 children with various disorders used as controls. They were undetectable by ultraviolet light at room temperature. Their $\mathbf{R}_{\mathrm{f}}$ values, colour of emitted light, duration of phosphorescence, and detection sensitivity are shown in the Table. Spraying the chromatogram with $1 \mathrm{~N}$ hydrochloric acid abolished phosphorescence due to deoxyadenosine and deoxyguanosine.

There were several phosphorescent compounds in control urine which we have not yet identified. It is of interest that the urine of child (SB) lacked all of these compounds, which were regularly present in control urine. Standards have been chromatographed of the following compounds: adenine, guanine, hypoxanthine, xanthine, adenosine, guanosine, inosine, deoxyinosine, thymine, thymidine, uracil, uridine, cytosine, uric acid,

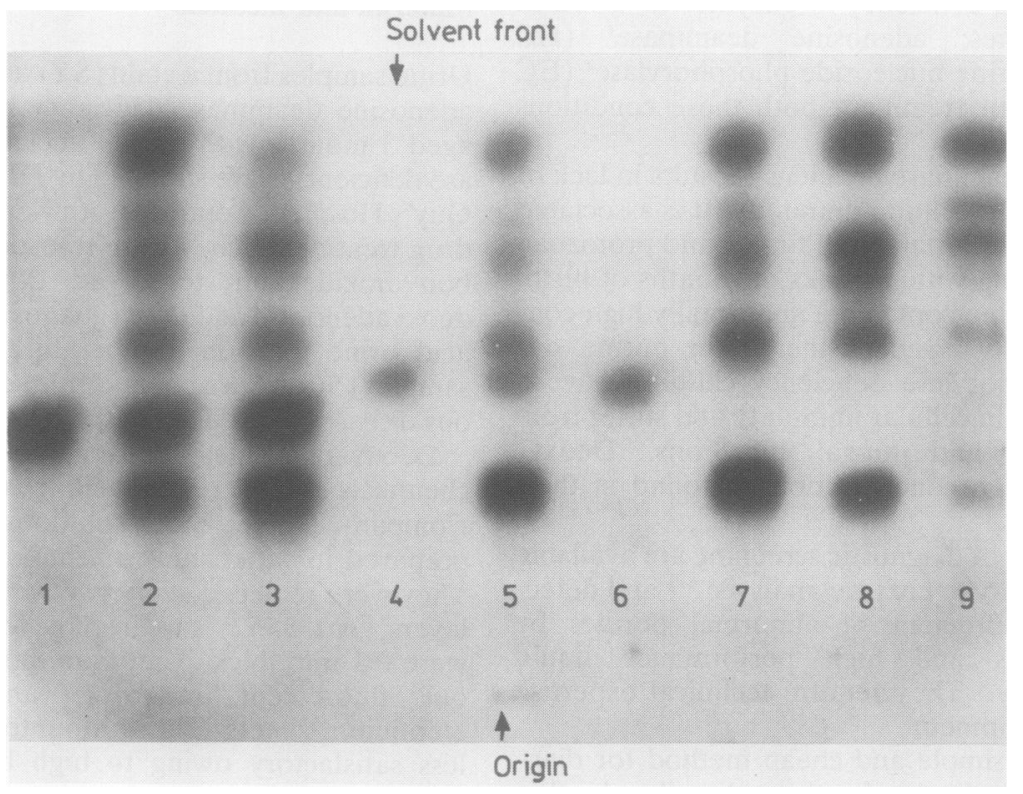

Photograph of an $x$ ray film which was placed on a cellulose thin layer chromatogram, immersed in liquid nitrogen, after exposure to ultraviolet light at 254 $\mathrm{nm}$. One microlitre was applied of each of the following: (1) Deoxyadenosine (1 $n$ mole) in water; (2) deoxyadenosine (1 $n$ mole in normal urine; (3) adenosine deaminase deficiency urine (SY); (4) deoxyguanosine (1 $n$ mole) in water; (5) deoxyguanosine (1 $n$ mole) in normal urine; (6) purine nucleoside phosphorylase deficiency urine; (7-9) control urines. 
Properties of substances detected in urine in adenosine deaminase deficiency (SY) and purine nucleoside phosphorylase deficiency $(S B)$

\begin{tabular}{lllll}
\hline & $\begin{array}{l}\boldsymbol{R}_{f} \\
\text { value }\end{array}$ & $\begin{array}{l}\text { Band } \\
\text { colour }\end{array}$ & $\begin{array}{l}\text { Decay } \\
\text { time }(s)\end{array}$ & $\begin{array}{l}\text { Detection } \\
\text { sensitivity } \\
(\boldsymbol{p} \text { mole })\end{array}$ \\
\hline Deoxyadenosine in water & 0.44 & Blue & 16 & 32 \\
Deoxyadenosine in urine & 0.44 & Blue & 16 & 32 \\
Urine (SY) & 0.44 & Blue & 14 & \\
Deoxyguanosine in water & 0.50 & Blue & 7 & 60 \\
Deoxyguanosine in urine & 0.50 & Blue & 7 & 60 \\
Urine (SB) & 0.49 & Blue & 7 & \\
\hline
\end{tabular}

$R_{\mathrm{f}}$ value $=$ distance run by substance divided by distance run by solvent.

2,8-dihydroxyadenine, 1-methylhypoxanthine, 7-methylhypoxanthine, and caffeine. None of these corresponded to the phosphorescent compounds in control urine.

No phosphorescent compounds were detected in one sample of normal amniotic fluid by this method, although added standards of deoxyadenosine and deoxyguanosine were easily detected.

\section{Discussion}

The absence of deoxyadenosine and deoxyguanosine in unaffected individuals allows the simple qualitative detection of these compounds to be used for diagnosis. Four of their physicochemical properties can be easily recorded so that high specificity is obtained with little effort. This test can be done using less than $1 \mu$ l of urine and the abnormal urinary purines are easy to detect.

The absence of all the phosphorescent compounds normally present in control urine from the urine of the child with purine nucleoside phosphorylase deficiency is of great interest. This observation requires confirmation as it might throw some light on the extent of the biochemical disturbances involved and their relation to immunodeficiency.

We have described a method of diagnostic screening for adenosine deaminase and purine nucleoside phosphorylase deficiency that can be done in any hospital laboratory by unskilled staff. It is inexpensive to perform and a permanent record on $x$ ray film may be obtained.
References

' Giblett ER, Anderson JE, Cohen F, Pollara B, Meuwissen HJ. Adenosine deaminase deficiency in the patients with severely impaired cellular immunity. Lancet 1972; ii: 1067-9.

${ }^{2}$ Giblett ER, Amman AJ, Sandman R, Wara DW, Diamond IK. Nucleoside phosphorylase deficiency in a child with severely defective T-cell immunity and normal B-cell immunity. Lancet 1975;ii: 1010-3.

${ }^{3}$ Simmonds HA, Sahota A, Potter CF, Cameron JS. Purine metabolism immunodeficiency: urinary purine excretion as a diagnostic screening test in adenosine deaminase and purine nucleoside phosphorylase deficiency. Clin Sci Mol Med 1978;54:579-84.

4 Donofrio J, Coleman MS, Hutton JJ, Daoud DA. Overproduction of adenosine deoxynucleosides and deoxynucleotides in adenosine deaminase deficiency with severe combined immunodeficiency disease. J Clin Invest 1978;62:884-7.

${ }^{5}$ Mills GC, Goldbnum RM, Newkirk KE, Schmalstieg FC. Urinary excretion of purines, purine nucleosides and pseudouridine in adenosine deaminase deficiency. Biochem Med 1978;20:180-99.

- Cohen A, Doyle D, Martin DWJ, Amman AJ. Abnormal purine metabolism and purine overproduction in a patient deficient in purine nucleoside phosphorylase. $N$ Engl J Med 1976; 295: 1449-54.

' Stoop JW, Zegers BJM, Hendrickx GFM. Purine nucleoside phosphorylase deficiency and cellular immunodeficiency. $N$ Engl J Med 1977;296:651-5.

${ }^{8}$ Kalckar HM. Differential spectrophotometry of purine compounds by means of specific enzymes. J Biol Chem 1947;167:461-75.

- Spencer N, Hopkinson DA, Harris H. Adenosine deaminase polymorphism in man. Ann Hum Genet 1968;32:9-14.

${ }^{10}$ Hopkinson DA, Cook PJL, Harris H. Further data on the adenosine deaminase (ADA) polymorphism and a report of a new phenotype. Ann Hum Genet 1969;32:361-7.

" Edwards JH, Hopkinson DA, Harris H. Inherited variants of human nucleoside phosphorylase. Ann Hum Genet 1971;34:395-408.

${ }^{12}$ Steele RH, Szent-Gyorgy A. On excitation of biological substances. Proc Natl Acad Sci 1957;43:477-91.

${ }^{13}$ Cohen A, Martin DW, Amman AJ. Abnormal levels of purine metabolites in the serum and urine of a purine nucleoside phosphorylase deficient child. J Clin Chem Clin Biochem 1976;14:283-4.

${ }^{14}$ Maddocks JL, Davidson GS. Separation and detection of picomole quantities of azathioprine metabolites. Br J Clin Pharmacol 1975;2:359-60.

Requests for reprints to: Dr JL Maddocks, Department of Therapeutics, University of Sheffield, Royal Hallamshire Hospital, Glossop Road, Sheffield S10 2JF, England. 